\title{
Risk Tolerance: A Measurement Tool for Financial Novices
}

\author{
Kadir C. Yalcin \\ Valdosta State University
}

Assessing a risk tolerance is vital for healthy financial decisions. Common surveys used to assess risk tolerance use language and jargon beyond the scope of financial novices. The purpose of this study is to develop an instrument to measure and evaluate the financial risk tolerance of the financial novices by providing a questionnaire that can be easily and quickly completed. The paper statistically documents that the Covid-19 has no impact on financial risk tolerance level, male participants are more risk tolerant than female participants, and there is a significant association between gender and the risk tolerance level among the non-minority participants.

Keywords: financial risk tolerance, financial novices, survey-based measurement

\section{INTRODUCTION}

Researchers have long been interested in understanding how investors behave and make financial decisions. There are many factors that that affect investors' decisions. Some of them are income level, macro-economic and political factors, behavioral factors and etc. The behavioral factors can be classified as time horizon, behavioral biases and risk tolerance.

Many brokerage firms' questionnaires start with questions like 'when do you begin to withdraw money from this investment account' or 'when will you think to retire'. The idea behind these types questions is to understand the investor's time horizon. Indeed, time horizon is one of the important factors that shape the investment decision. Because investment instruments have different maturities. For example, there are 13 weeks Treasury Bills, 10 years Treasury Notes and 30 years Treasury Bonds. All are the debt securities backed by the US Treasury, that means no default-risk. However, returns are varying depends on the maturity. It is generally assumed that longer periods mean higher risk. In other words, how much risk that much return because the risk and the return are twin brothers. But, the return is something like a two-sided medallion. One side is the positive return and the other is the negative return. For instance, derivative markets are one of the riskiest markets because the investment decisions are usually taken by using high level of leverage which can easily magnify the gain or loss.

Biases are people's systematic errors of judgments when he or she decides on something (Kahneman and Riepe, 1998). They can be classified into four sub-groups; (i) Self-Deception, (ii) Heuristics, (iii) Emotions and Sentiments, (iv) Social Interaction (Hirshleifer, 2001).

Self-deception is the individuals' tendency to see himself or herself as more talented, smarter and better than others (Montier, 2002). Heuristics are the shortcuts used to reduce the mental efforts in order to simplify the complex tasks and make the decision process easier (Tversky and Kahneman, 1974). Emotions and sentiments such as pride, regret, hate, fear and greed make us human and people's preferences are 
highly affected by these emotions (Elvin, 2004). Social interaction in the form of social contagion, imitation and herd behavior affect people's tendency to think and behave like the group without investigating their accuracy. Because people have tendency to accept ideas within the group because they tend to remember the ideas, conversations, rituals and symbols that are accepted by the group because of limited attention. people (Shiller, 1998).

The other important factor that affects the financial decision is the financial risk tolerance level (Grable and Lytton, 1999). It defined as the maximum amount of uncertainty that someone is willing to accept when making a financial decision (Grable 2000, pp. 625). In other words, it is an individual appetite for risk. At this point, it is important to clarify the difference between the risk capacity and risk tolerance. The risk capacity is an individual capacity to afford how much risk whereas the risk tolerance is an individual choice to take how much risk (Roszkowski et al., 2005). The individual risk capacity is affected by some observable factors like income level and number of dependents, but it is also affected by the psychological factors like the life s/he wants to live when s/he is young and old. Since the purpose of this research is to develop a measurement in order to assess an individual choice to take how much risk under different scenarios, I focus on the risk tolerance.

Very frequently, human behavior is unclear and unpredictable in nature. Despite the fact that it is too hard to measure financial risk tolerance according to MacCrimmon and Wehrung (1986), the best way is to use carefully designed survey. So, the question is how to carefully design a survey. There are at least three criteria that must be met for designing a good survey.

First of all, we are living in a very fast world. We eat foods very fast, digest news very fast, start and break-up a relationship very fast and etc. Therefore, a good questionnaire must be short and very easy to complete. Second, a good questionnaire's language must be very simple. Technical jargon and terminology should be eliminated. Otherwise, the understandability decreases and an explanation is needed which ultimately cause a framing. When participants are framed with verbal explanations, the objectivity of the test decreases. Third, a questionnaire must be completely anonymous. No one shouldn't be able to associate participants' responses with their identity. Fourth, participation must be voluntary and participants should not receive no direct benefits from participating in research. Lastly, a good questionnaire must be statistically reliable.

\section{METHODS}

The purpose of this research is to develop a measurement tool in order to assess the financial risk tolerance level of financial novices. The research is designed as a survey and is prepared in four phases. In the first phase, survey-based researches including Grable and Lytton (1999), FinaMetrica (An Australianbased risk profiling assessment company), Charles Schwab, TIAA, Valic, Fidelity and other leading brokerage firms' and investment fund management companies' questionnaires about risk profiling are carefully examined.

Second, as Roszkowski et al. (2005) suggests, a large set of questions is generated and tested on representative samples of the population in order to understand whether the questions can be understood clearly by the targeted group. Since the targeted group is the students who are taking Financial Health in Modern Societies (formerly Personal Finance) course all the technical jargon and terminology have been eliminated since the concept of bonds, stocks and etc. cannot be easily understood by the financial novices.

Third, the selected questions were tested as in-class activities with students in numerous times. The answers were taken and evaluated while their comprehension of the questions was observed. Since the targeted group is the financial novices, it is observed that students' minds are confused when there are more than three options. Therefore, more than three options in questions was not given.

Lastly, the pilot was given to the professors who have Ph.D. in finance and related areas for further fine tuning of the questions. The items for an instrument were selected, an item analysis was conducted and index scores were created as recommended by Grable and Lytton (1999).

After these phases, the questionnaire was finalized (see Appendix) and it was approved by the Valdosta State University's Institutional Review Board. The survey is part of the instructional project supported by 
the Langdale College of Business Administration Steele Grant for helping the first-year students taking Financial Health in Modern Societies course in order to assess their risk tolerance level. The data collection was administered in October-November 2019 and October-November 2020.

Cronbach's alpha of reliability coefficient is used to create the optimal scale on aggregate. Once internal consistency is achieved, the total score of the aggregated scale is then calculated by using the index scores for each item. The Shapiro-Wilk statistic for normality is employed in order to determine if parametric or non-parametric statistics will be used to test the following hypotheses:

$\boldsymbol{H}_{1}$ : The Covid-19 has impact on financial risk tolerance level.

$\boldsymbol{H}_{2}:$ Male students are more risk tolerant than female students.

$\boldsymbol{H}_{3}:$ Self-identified minority students are more risk tolerant than non-self-identified minority students.

\section{RESULTS AND DISCUSSION}

A total of 544 students responded resulting in 522 fully completed surveys. Table 1 provides the demographic characteristics of sample.

TABLE 1

DEMOGRAPHIC CHARACTERISTICS OF SAMPLE

\begin{tabular}{c|c|c|c}
\hline \multirow{3}{*}{ Completion Time } & October-November 2019 & Frequency & Percent \\
& October-November 2020 & 283 & 54.2 \\
\multirow{2}{*}{ Gender } & Male & 248 & 45.8 \\
\hline \multirow{2}{*}{ Minority Status } & Female & 274 & 47.5 \\
& non-Minority & 256 & 52.5 \\
\hline
\end{tabular}

In assessing reliability through Cronbach's Alpha, some authors suggest different levels of acceptance. Nunnally and Bernstein (1994) suggest a rule of thumb level of higher than 0.60 being accepted for new scale. Table 2 provides the reliability statistics by using the Cronbach's Alpha of reliability coefficient for internal consistency.

TABLE 2

INTERNAL CONSISTENCY RELIABILITY STATISTICS

\begin{tabular}{|c|c|c|}
\hline $\begin{array}{c}\text { Cronbach's Alpha } \\
0.616\end{array}$ & $\begin{array}{c}\text { Cronbach's Alpha Based } \\
\text { on Standardized Items } \\
0.618\end{array}$ & $\begin{array}{c}\mathrm{N} \text { of Items } \\
4\end{array}$ \\
\hline Question Item & Mean & $\begin{array}{c}\text { Cronbach's Alpha if Item } \\
\text { Deleted }\end{array}$ \\
\hline Item \#1 & 1.82 & 0.528 \\
\hline Item \#2 & 2.16 & 0.566 \\
\hline Item \#3 & 2.08 & 0.569 \\
\hline Item \#4 & 1.79 & 0.523 \\
\hline
\end{tabular}


Table 3 provides evidence that the scale is not normally distributed; therefore, non-parametric statistic Mann-Whitney $U$ is used to analyze the association between the total scores (see Appendix for the index scores) and (i) the completion time (pre-Covid-19 vs. during Covid-19), (ii) gender, (iii) minority status.

\section{TABLE 3 \\ TEST OF NORMALITY}

\begin{tabular}{c|c|c|c}
\hline Shapiro-Wilk & Statistic & df & Sig. \\
\hline Risk Tolerance Scale & 0.958 & 522 & 0.000 \\
\hline
\end{tabular}

The coronavirus disease (Covid-19) pandemic started in December 2019 in China. There was no Covid19 case in the U.S. in October-November 2019. As provided in Table 1, 54.2\% of the survey were fully completed in the pre-Covid-19 era (October-November 2019), and $45.8 \%$ of the survey were fully completed during the pandemic (October-November 2020). A Mann-Whitney U test revealed no significant difference in the risk tolerance score of the students in the pre-Covid-19 era $(\mathrm{Md}=8, \mathrm{n}=283)$ and during the Covid-19 era $(\mathrm{Md}=8, \mathrm{n}=239), \mathrm{U}=34949, \mathrm{z}=0.668, \mathrm{p}=0.504, \mathrm{r}=0.029$. Therefore, the Covid-19 has no impact on financial risk tolerance score.

A Mann-Whitney $\mathrm{U}$ test revealed a significant difference in the risk tolerance scores of males $(\mathrm{Md}=8$, $\mathrm{n}=248)$ and females $(\mathrm{Md}=8, \mathrm{n}=274), \mathrm{U}=30550.5, \mathrm{z}=-2.019, \mathrm{p}=0.044$, and no significant difference in the risk tolerance scores of self-identified minority students $(\mathrm{Md}=8, \mathrm{n}=256)$ and non-self-identified minority students $(\mathrm{Md}=8, \mathrm{n}=266), \mathrm{U}=32111.5, \mathrm{z}=-1.140, \mathrm{p}=0.254, \mathrm{r}=0.049$. Therefore, male students are more risk tolerant than female students in terms of scores, but the minority status has no impact on financial risk scores.

In order to identify the risk tolerance level of the participants, the levels are categorized as low, moderate, and high by using the index scores (see Appendix). The categorizations exhibit that the $28.5 \%$ of all participants have low-risk tolerance level, $46 \%$ of them have moderate-risk tolerance level, and $25.5 \%$ of them have high-risk tolerance level. The chi-square test for independence is used to analyze the association between the risk tolerance levels and the completion time, gender, and the minority status.

A chi-square test for independence indicated that no significant association between the completion time and the risk tolerance level, $\mathrm{x} 2(2, \mathrm{n}=522)=0.795, \mathrm{p}=0.672$, Cramer's $\mathrm{V}=0.039$. Table 4 provides the gender and risk tolerance level crosstabulation.

\section{TABLE 4}

\section{COMPLETION TIME * RISK TOLERANCE LEVEL CROSSTABULATION}

\begin{tabular}{|c|c|c|c|c|c|c|}
\hline & & & \multicolumn{3}{|c|}{ Risk Tolerance Level } & \multirow{2}{*}{ Total } \\
\hline & & & Low & Moderate & High & \\
\hline \multirow{4}{*}{$\begin{array}{l}\text { Completion } \\
\text { Time }\end{array}$} & \multirow{2}{*}{$\begin{array}{l}\text { Pre-Covid- } \\
19\end{array}$} & Count & 85 & 129 & 69 & 283 \\
\hline & & $\begin{array}{c}\% \text { within Completion } \\
\text { Time }\end{array}$ & $30.0 \%$ & $45.6 \%$ & $24.4 \%$ & $100 \%$ \\
\hline & \multirow{2}{*}{$\begin{array}{l}\text { During } \\
\text { Covid-19 }\end{array}$} & Count & 64 & 111 & 64 & 196 \\
\hline & & $\begin{array}{c}\% \text { within Completion } \\
\text { Time } \\
\end{array}$ & $26.8 \%$ & $46.4 \%$ & $26.8 \%$ & $100 \%$ \\
\hline \multirow{2}{*}{\multicolumn{2}{|c|}{ Total }} & Count & 149 & 240 & 133 & 522 \\
\hline & & $\begin{array}{c}\% \text { within Completion } \\
\text { Time }\end{array}$ & $28.5 \%$ & $46 \%$ & $25.5 \%$ & $100 \%$ \\
\hline
\end{tabular}


It is surprising to see the decrease in the low-risk tolerance level group despite it is not too much. $30 \%$ of participants had low-risk tolerance level before the Covid-19 pandemic (October-November 2019), and it decreased to $26.8 \%$ during the Covid-19 era (October-November 2020). There are slight increases in the moderate and high-risk tolerance levels. However, none of the changes are statistically meaningful.

A chi-square test for independence indicated a significant association between gender and the risk tolerance level, $\mathrm{x} 2(2, \mathrm{n}=522)=9.917, \mathrm{p}=0.007$, Cramer's $\mathrm{V}=0.138$. Table 5 provides the gender and risk tolerance level group crosstabulation.

TABLE 5

GENDER * RISK TOLERANCE LEVEL CROSSTABULATION

\begin{tabular}{|c|c|c|c|c|c|c|}
\hline & & & \multicolumn{3}{|c|}{ Risk Tolerance Level } & \multirow{2}{*}{ Total } \\
\hline & & & Low & Moderate & High & \\
\hline \multirow{4}{*}{ Gender } & \multirow{2}{*}{ Male } & Count & 70 & 100 & 78 & 248 \\
\hline & & $\%$ within Gender & $28.2 \%$ & $40.3 \%$ & $31.5 \%$ & $100 \%$ \\
\hline & \multirow{2}{*}{ Female } & Count & 79 & 140 & 55 & 196 \\
\hline & & $\%$ within Gender & $28.8 \%$ & $51.1 \%$ & $20.1 \%$ & $100 \%$ \\
\hline \multirow{2}{*}{\multicolumn{2}{|c|}{ Total }} & Count & 149 & 240 & 133 & 522 \\
\hline & & $\%$ within Gender & $28.5 \%$ & $46.0 \%$ & $25.5 \%$ & $100 \%$ \\
\hline
\end{tabular}

$31.5 \%$ of male participants have high-risk tolerance level whereas only $20.1 \%$ of female participants have high-risk tolerance level. On the other hand, $51.1 \%$ of female participants have moderate-risk tolerance level whereas $40.1 \%$ of male participants have moderate-risk tolerance level. Male and female participants have very closed low-risk tolerance levels (28.2\% and $28.8 \%)$.

A chi-square test for independence indicated that no significant association between minority status and the risk tolerance level, $\mathrm{x} 2(2, \mathrm{n}=522)=5.600, \mathrm{p}=0.061$, Cramer's $\mathrm{V}=0.104$. Table 6 provides the minority status and the risk tolerance level crosstabulation.

TABLE 6

MINORITY STATUS * RISK TOLERANCE LEVEL CROSSTABULATION

\begin{tabular}{|c|c|c|c|c|c|c|}
\hline & & & \multicolumn{3}{|c|}{ Risk Tolerance Level } & \multirow{2}{*}{ Total } \\
\hline & & & Low & Moderate & High & \\
\hline \multirow{6}{*}{$\begin{array}{l}\text { Minority } \\
\text { Status }\end{array}$} & \multirow{2}{*}{$\begin{array}{l}\text { non- } \\
\text { Minority }\end{array}$} & Count & 63 & 118 & 75 & 256 \\
\hline & & $\begin{array}{c}\% \text { within } \\
\text { Minority Status }\end{array}$ & $24.6 \%$ & $46.1 \%$ & $29.3 \%$ & $100 \%$ \\
\hline & \multirow[b]{2}{*}{ Minority } & Count & 86 & 122 & 58 & 266 \\
\hline & & $\begin{array}{c}\% \text { within } \\
\text { Minority Status }\end{array}$ & $32.3 \%$ & $45.9 \%$ & $21.8 \%$ & $100 \%$ \\
\hline & \multirow[b]{2}{*}{ Total } & Count & 149 & 240 & 133 & 522 \\
\hline & & $\begin{array}{c}\% \text { within } \\
\text { Minority Status }\end{array}$ & $28.5 \%$ & $46 \%$ & $25.5 \%$ & $100 \%$ \\
\hline
\end{tabular}


Even though it is not statistically proven, it is worth to note that the percentage differences in the low and high-risk tolerance levels in terms of the minority status. $32.3 \%$ of the minority students have low-risk tolerance level whereas $24.6 \%$ of the non-minority students have low-risk tolerance level. On the other hand, $29.3 \%$ of the non-minority students have high-risk tolerance level whereas $21.8 \%$ of the minority students have high-risk tolerance level. There is no much percentage difference between the minority and non-minority students in the moderate-risk tolerance level.

Moreover, a chi-square test for independence was conducted in order to explore the effect of minority status over the association of gender and the risk tolerance level. The results revealed that there is a significant association between gender and the risk tolerance level among the non-minority students, $\mathrm{x} 2(2$, $\mathrm{n}=256)=12.073, \mathrm{p}=0.002$, Cramer's $\mathrm{V}=0.217$; however, there is no significant association between gender and the risk tolerance level among the minority students, $x 2(2, n=266)=0.499, p=0.779$, Cramer's $\mathrm{V}=0.043$. Table 7 provides the gender and risk tolerance level group crosstabulation in terms of the minority status.

TABLE 7

GENDER * RISK TOLERANCE LEVEL *MINORITY STATUS CROSSTABULATION

\begin{tabular}{|c|c|c|c|c|c|c|c|}
\hline \multirow{2}{*}{$\begin{array}{l}\text { Minority } \\
\text { Status }\end{array}$} & & & & \multicolumn{3}{|c|}{ Risk Tolerance Level } & \multirow[b]{2}{*}{ Total } \\
\hline & & & & Low & Moderate & High & \\
\hline \multirow{6}{*}{$\begin{array}{l}\text { non- } \\
\text { Minority }\end{array}$} & \multirow{4}{*}{ Gender } & \multirow{2}{*}{ Male } & Count & 33 & 50 & 51 & 134 \\
\hline & & & $\%$ within Gender & $24.6 \%$ & $37.3 \%$ & $38.1 \%$ & $100 \%$ \\
\hline & & \multirow{4}{*}{ Female } & Count & 30 & 68 & 24 & 122 \\
\hline & & & $\%$ within Gender & $24.6 \%$ & $55.7 \%$ & $19.7 \%$ & $100 \%$ \\
\hline & Total & & Count & 63 & 118 & 75 & 256 \\
\hline & & & $\%$ within Gender & $24.6 \%$ & $46.1 \%$ & $29.3 \%$ & $100 \%$ \\
\hline \multirow{6}{*}{ Minority } & \multirow{4}{*}{ Gen } & \multirow{2}{*}{ Male } & Count & 37 & 50 & 27 & 114 \\
\hline & & & $\%$ within Gender & $32.5 \%$ & $43.9 \%$ & $23.7 \%$ & $100 \%$ \\
\hline & & \multirow{2}{*}{ Female } & Count & 49 & 72 & 31 & 152 \\
\hline & & & $\%$ within Gender & $32.2 \%$ & $47.4 \%$ & $20.4 \%$ & $100 \%$ \\
\hline & \multirow[t]{2}{*}{ Total } & & Count & 86 & 122 & 58 & 266 \\
\hline & & & $\%$ within Gender & $32.3 \%$ & $45.9 \%$ & $21.8 \%$ & $100 \%$ \\
\hline
\end{tabular}

Male participants have higher risk tolerance level over the female participants among the non-minority participants as $38.1 \%$ of the male participants have high-risk tolerance level whereas only $19.1 \%$ of the female participants have high-risk tolerance level. We cannot observe that kind of disparity between the male and female participants who have the high-risk tolerance level among minority students $(23.7 \%$ vs. 20.4\%). Moreover, there is a disparity between the male non-minority participants and male minority students who have the high-risk tolerance level (38.1\% vs $23.7 \%)$. That kind of disparity cannot not be observed the between the female non-minority participants and female minority students who have highrisk tolerance level (19.7\% vs $20.4 \%)$.

On the other hand, the female participants have higher risk tolerance level over the male participants among non-minority participants as $55.7 \%$ of the female participants have the moderate-risk tolerance level whereas $40.1 \%$ of the male participants have the moderate-risk tolerance level.

\section{CONCLUSION}

Income inequality even among developed countries is at historical levels; empirical research supports the hypothesis that lack of financial knowledge exacerbates wealth inequality. Assessing a risk tolerance is vital in order to get healthy financial decisions. Unfortunately, common surveys used to assess risk tolerance use language and jargon beyond the scope of many people. This paper provides a survey-based 
measurement tool that can be easily and quickly done by the financial novices. It was written in a language easily understood and can be completed by financially inexperienced participants yet evaluative at the same time. The results of this paper show that $28.5 \%$ of all participants have low-risk tolerance level, $46 \%$ of them have moderate-risk tolerance level, and $25.5 \%$ of them have high-risk tolerance level. It is statistically proven that the Covid-19 has no impact on financial risk tolerance level. Male students are more risk tolerant than female students and there is a significant association between gender and the risk tolerance level among the non-minority students. However, there is no statistical difference in the risk tolerance levels of minority students and non-minority students. The results are limited to sample size, number of self-identified minority respondents, and non-normality of the data.

\section{REFERENCES}

Elvin, M. (2004). Financial Risk Taking: An Introduction to the Psychology of Trading and Behavioural Finance. West Sussex, England: John Wiley \& Sons.

FinaMetrica. (n.d.). [Online]. Retrieved May 3, 2019, from www.riskprofiling.com

Grable, J., \& Lytton, R.H. (1999). Financial Risk Tolerance Revisited: The Development of Risk Assessment Instrument. Financial Services Review, 8, 163-181.

Grable, J.E. (2000). Financial Risk Tolerance and Additional Factors That Affect Risk Taking in Everyday Money Matters. Journal of Business and Psychology, 14(4), 625-630.

Hirshleifer, D. (2001). Investor Psychology and Asset Pricing. Journal of Finance, 56(4), 1533-1597.

Kahneman, D., \& Riepe, M.W. (1998). Aspects of Investor Psychology. Journal of Portfolio Management, 24(4), 52-65.

MacCrimmon, K.R., \& Wehrung, D.A. (1986). Taking Risks: The Management of Uncertainty. The Free Press. New York.

Montier, J. (2002). Part Man Part Monkey. Global Equity Strategy. Dresdner Kleinwort Wasserstein Research Report, pp. 1-12.

Nunnally, J.C., \& Bernstein, I.H. (1994). Psychometric Theory (3rd ed.). New York: McGraw-Hill.

Roszkowski, M.J., Davey, G., \& Grable, J. (2005). Insights from Psychology and Psychometrics on Measuring Risk Tolerance. Journal of Financial Planning, 18(4), 66-77.

Shiller, R. (1998). Human behavior and the efficiency of the financial system. NBER Working Paper, W6375.

Tversky, A., \& Kahneman, D. (1974). Judgment Under Uncertainty: Heuristics and Biases. Science, 185(4157), 1124-1131.

\section{APPENDIX}

1. You have an opportunity to make an investment that will probably to produce a sizeable return but without a guarantee. However, you have no funds to put towards this investment. One option is to borrow money for this purpose. How likely is it that you would borrow the money and invest?
a. Unlikely
b. Somewhat likely
c. Absolutely

2. In addition to whatever you own, you are given $\$ 1,000$. You are now asked to invest this $\$ 1,000$ based on the three results below. The chance of winning or losing is $50 \%$. Which investment option do you prefer?

a. The potential of earning extra $\$ 100$ but the risk of losing $\$ 50$.

b. The potential of earning extra $\$ 500$ but the risk of losing $\$ 250$.

c. The potential of earning extra $\$ 1,000$ but the risk of losing $\$ 500$.

3. Assume that a long-lost relative dies and leaves you a house which is in poor condition but is located in a suburb that's becoming popular. As is, the house would probably sell for $\$ 300,000$, but if you were to spend about $\$ 100,000$ on renovations, the selling price would be around $\$ 600,000$. You will have to borrow the $\$ 100,000$ from a bank (take out a mortgage), and the bank will own (foreclose on) the house if the loan is not repaid in full. Also, there is some talk of constructing a 
major highway next to the house, and this would lower its value considerably. Which of the following options would you take?

a. Sell it as is.

b. Keep it as is, but rent it out.

c. Take out a $\$ 100,000$ mortgage and do the renovations.

4. Suppose you are on TV game show you've just won $\$ 5,000$. Now you must choose between quitting with the $\$ 5,000$ in hand or betting the entire $\$ 5,000$ in one of two alternative scenarios that could result a higher return or losing the $\$ 5,000$. Which of the following options would you choose?

Option A: Don't take the bet. Take $\$ 5,000$ and quit the game.

Option B: Take the bet in order to earn $\$ 25,000$ with a $50 \%$ chance.

Option C: Take the bet in order to earn $\$ 100,000$ with a $25 \%$ chance.

Add up your score, using the following key:

Scoring

1) $a: 1 \quad b: 2 \quad c: 3$

2) $a: 1 \quad b: 2 \quad c: 3$

3) $a: 1 \quad b: 2 \quad c: 3$

4) $a: 1 \quad b: 2 \quad c: 3$

Risk Tolerance Level $\underline{\text { Score }}$

Conservative (Low) Risk Tolerance...... $4-6$

Moderate (Normal) Risk Tolerance....... 7 - 9

Aggressive (High) Risk Tolerance........10 - 12 